\title{
Analysis of causes of the end of service life of a spray polyurethane foam and polyurea roof
}

\author{
Targo Kalamees ${ }^{1,2 *}$, Simo Ilomets ${ }^{2}$, Mattias Põldaru², Paul Klõseiko ${ }^{2}$, Urve Kallavus ${ }^{3}$, Margit Rosenberg ${ }^{2}$, Karl Õiger $^{2}$ \\ ${ }^{1}$ Smart City Center of Excellence (Finest Twins), Tallinn University of Technology, Ehitajate tee 5, Tallinn, Estonia \\ ${ }^{2}$ Department of Civil Engineering and Architecture, Tallinn University of Technology, Ehitajate tee 5, Tallinn, Estonia \\ ${ }^{3}$ Department of Mechanical and Industrial Engineering, Tallinn University of Technology, Ehitajate tee 5, Tallinn, Estonia
}

\begin{abstract}
Spray polyurethane foam (SPF) roofs are widely used in North America. Much fewer usage examples and experience can be found in Northern European cold climatic conditions. This study analyses hygrothermal performance and the reasons for the roof's degradation and end of service life of an SPF and polyurea roof. The service life of the roof is over and major reconstruction is needed eight year after construction. The current study uses field measurements included onsite temperature and humidity measurements and extensive surveying, the roof was opened from several locations and test samples were taken for laboratory tests. The influence of UV radiation on the loss of adhesion was tested. Solar radiation quickly degraded the top surface of the in-situ sprayed polyurethane foam insulation causing a weak connection between the foam layers. Due to mechanically damaged and UV degraded polyurea roofing, water has leaked into the SPF. The water inside or below the foam evaporated during sunny days and broke the adhesion of different foam layers. Larger foam blisters were observed on the upper part of the insulation caused by high water vapour pressure. This is considered the most realistic cause of separation of the SPF layers. The analyse of hygrothermal performance, service life, and durability prediction should be included into the design process, especially for structures with small or without long term performance experience.
\end{abstract}

\section{Introduction}

The purpose of the roof is to protect the building from weather Defects in roof affects the service life of the building. Air ventilation below the waterproofing is a typical solution in cold climate to improve the hygrothermal performance of roof structures [1-3].

A curved roof is more difficult to design and construct than a flat roof. If the roof's surface is not plain ensuring sufficient ventilation become more complicated due to geometrical reasons. The installation of thermal insulation and waterproofing material is also more complicated. 'In situ' sprayed polyurethane foam insulation (SPF) has been used for roofing applications from the middle of 1970's [4,5] and can would be suitable for curved roof applications. Sprayed Polyurethane Roofing System (SPRS) consists of a seamless sprayed-in-place SPF insulation covered with an elastomeric coating (EC). SPRS is widely used in America but has limited installation and performance experience in Northern European cold climate conditions.

This study analyses the durability, the performance and the reasons for the failure of a domed roof covered with SPRS. This case study demonstrates shortcomings of using structures from other climate regions with little or without long-term performance experience.

\section{Methods}

\subsection{Studied building}

The Tallinn seaplane hangar (Fig. 1) was designed and built in 1916-17 by the Danish company Christiani \& Nielsen. Tallinn seaplane hangar is among the first, remaining and still-preserved early large reinforcedconcrete shells in the world.

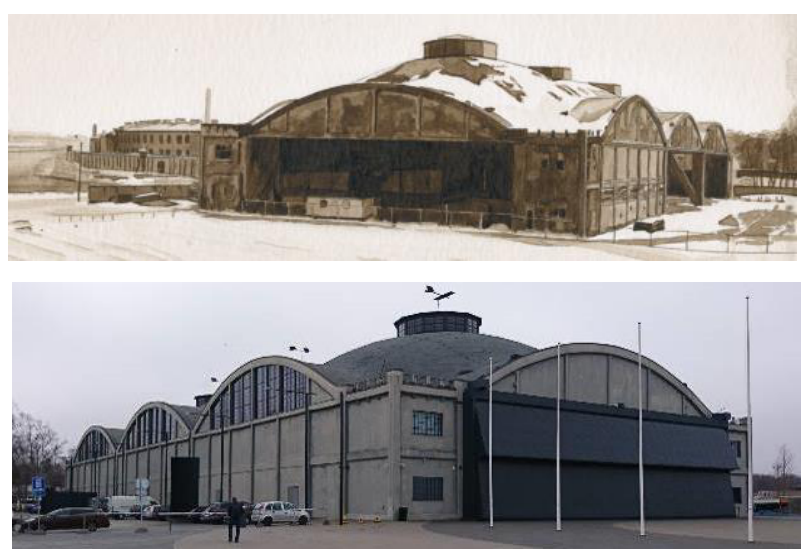

Fig. 1. Tallinn seaplane hangars before (above) [6] and after the renovation.

\footnotetext{
* Corresponding author: targo.kalamees@,taltech.ee
} 
The roof consists of three $36.4 \times 36.4 \mathrm{~m}$ spherical thin reinforced-concrete shells and seven $36.4 \times 6.8 \mathrm{~m}$ short cylindrical shells attached to them [7]. Originally, the roof was not insulated because the building was not heated. The upper surface of the hangar shells was covered with a kind of tar paper, however, it is not clear which exact material was used [8]. The roof lacked maintenance throughout the twentieth century and rainwater caused serious damage to the structure [9].

\subsection{Renovation of the building}

In 2010-2012 the seaplane hangar was reconstructed for the Estonian Maritime Museum. SPRS was added to the cupolas: $10 \mathrm{~cm}$ thermal insulation (sprayed closed cell polyurethane foam) + UV protection \& water-resistant layer to provide energy performance and stable climate conditions. Roof's fire protection section borders were insulated with mineral wool. The spray foam application was scheduled to begin in August 2010. However delays in the project delayed spray job and arriving Estonian winter conditions were not suitable for a quality spray job even below the temporary tent, therefore foam application was postponed [10].

SPRS installation started again in June next year, but then the installation was hindered by excessively moist concrete. Although the surface was visually dry and warm, it quickly became moist because of the exothermic reaction of the foam that brought the moisture to the concrete's surface. This caused weak adhesion to concrete, so foam could be easily pulled away after application and hardening. The use of a primer on the concrete was considered impossible due to a long delivery time. The installers also tried heating and drying the surface with propane gas burners with suboptimal results. Finally, the foam was sprayed along with the movement of the sun. The installers moved from one section of the domes to another following the warmth of the solar radiation. This increased exposure to UV radiation that is also the reason why already sprayed foam was degraded (Fig. 2). Once all the domes were sprayed with an initial layer and the weather had warmed, the installers re-traced their steps to spray a final layer of foam and apply an UV protective coating on the same working day.

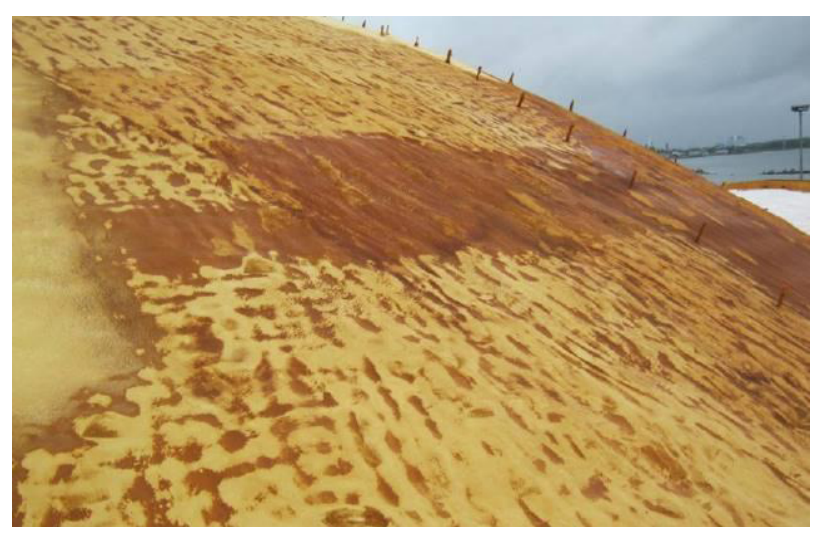

Fig. 2. Degradation of SPF due to solar radiation is visible as discoloration [11].

\subsection{Building survey and material measurement}

This study uses results from two surveys:

- The quality control during construction, 2011 [11]

(visual inspection and analysis of material samples);

- The roof survey by authors of this study, 2019.

- Visual inspection;

- Opening the roof structure in 24 locations;

- Measurement of temperature and humidity inside the SPFS and indoor the building;

- The moisture content of the material was measured using the gravimetric method.

- The water vapour transmission was measured according to EN ISO 12572 [12] and EN 12086 [13] standards.

- The pull off strength of SPF foam was measured in laboratory conditions similarly to standard method described in EN 1542 using the Proceq Dyna Z6 pull-off tester.

\section{Results}

\subsection{Technical condition of roof}

The following defects were identified during the survey, Fig. 3 and Fig. 4:

- The waterproofing and UV protection layer is worn out. Possibly problems with material quality and application of too thin layer;

- The waterproofing layer was not durable enough to resist occurring loads (including seagull loads);

- Lightning-rod fixers pierce waterproofing layer, causing leaks;

- Roof's parapet is not watertight;

- Upturn of waterproofing to the vertical surfaces is too narrow;

- Waterproofing connections with other building envelope parts are not watertight;

- Water has leaked inside the SPRS. In extreme cases the water flows below and inside the insulation;

- Water from inside the SPF leaks out through the waterproofing layer during some climate conditions, being visible on the roof on sunny days.

- UV radiation between has degraded the SPF under the blisters;

- The SPF upper layer has become detached from rest of the insulation. Large $(\approx 1 \mathrm{~m}$ radius $)$ foam blisters exist on the SPRS. The southern side of the roof has more and larger blisters;

- Many blisters were broken. 


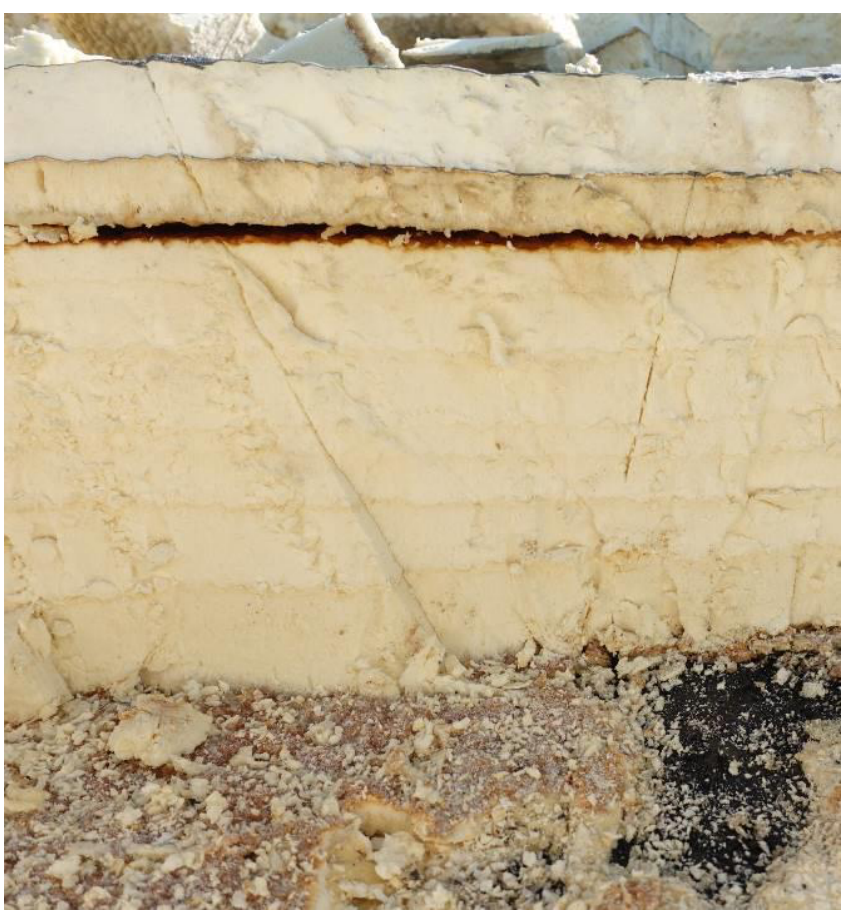

SPF upper layer has become detached from rest of the insulation. Large foam blisters exist on the SPRS.

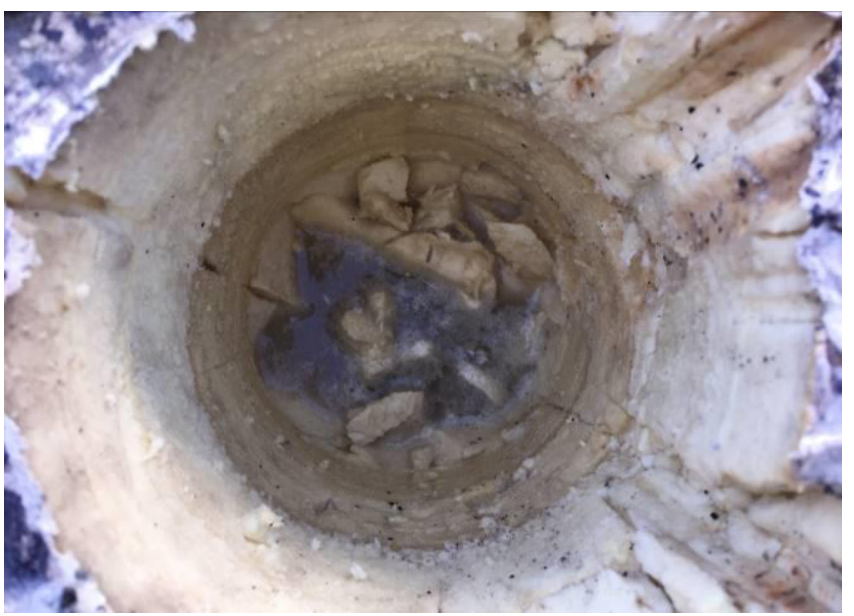

Watrer below and inside the insulatio

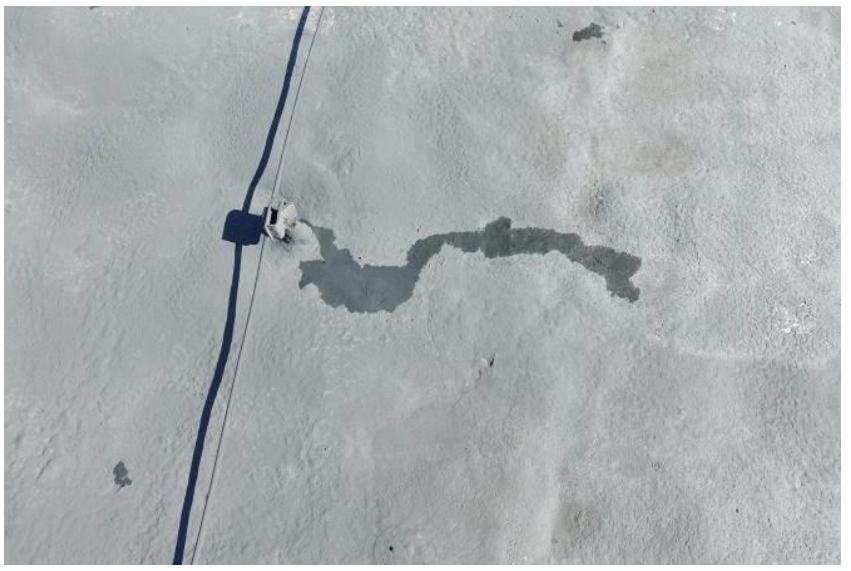

Water from the SPF leaks out through the waterproofing
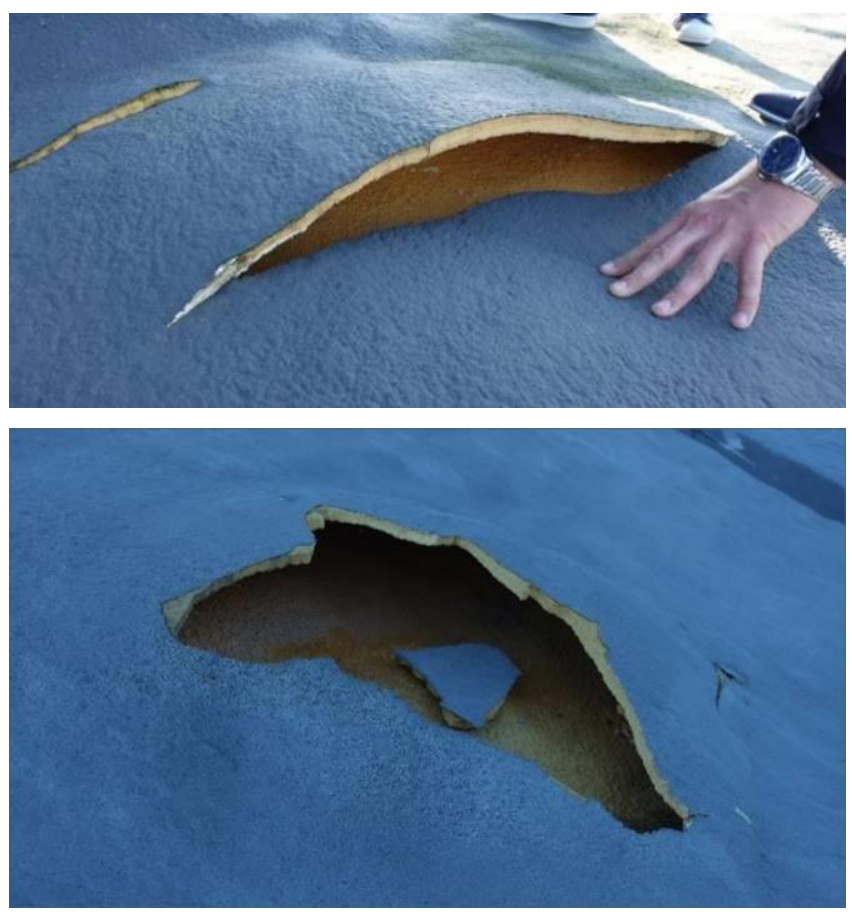

Many blisters were broken

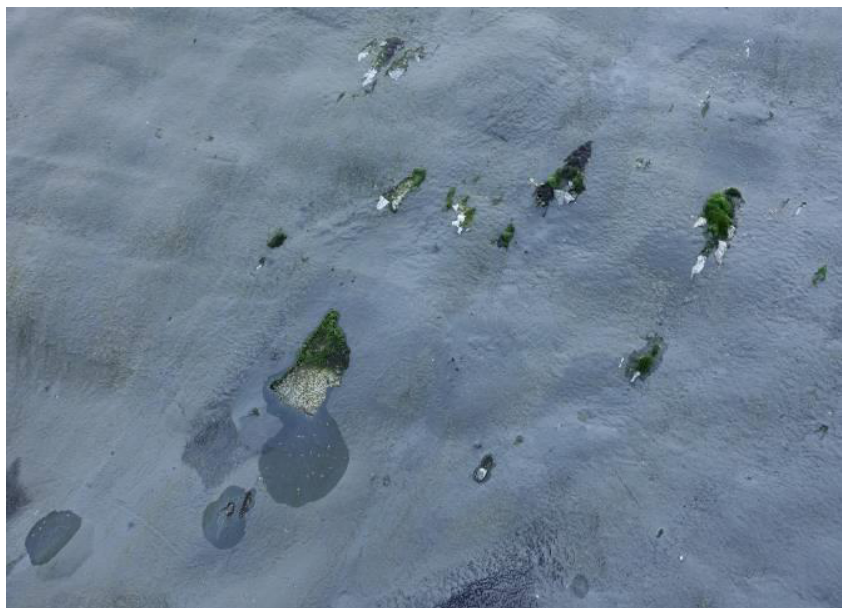

The waterproofing layer was not durable enough to resist occurring loads (including seagull loads)

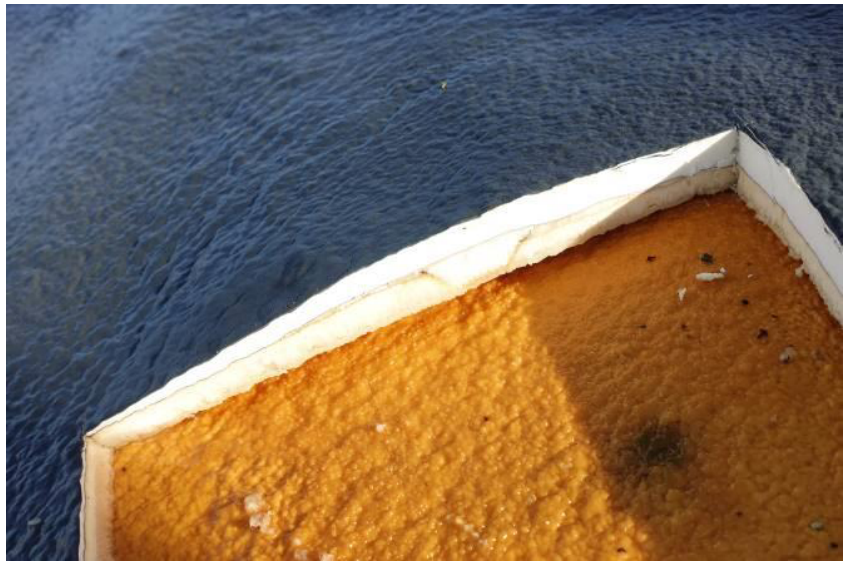

UV radiation between has degraded SPF below the blisters

Fig 3. Defects of the roof. 


\section{Temperature and humidity in roof}

The temperature below the waterproofing layer, $\approx 1 \mathrm{~cm}$ inside the insulation varied between $0{ }^{\circ} \mathrm{C}$ early in the morning and $56{ }^{\circ} \mathrm{C}$ (thin lines in Fig. 4 above) in the afternoon. Below the insulation (between the insulation and concrete shell) the temperature varied between 10 and $30^{\circ} \mathrm{C}$ (thick lines in Fig. 4 above). In four of five measurements points, a water vapour pressure reached saturation condition most of the time (Fig. 4 below).
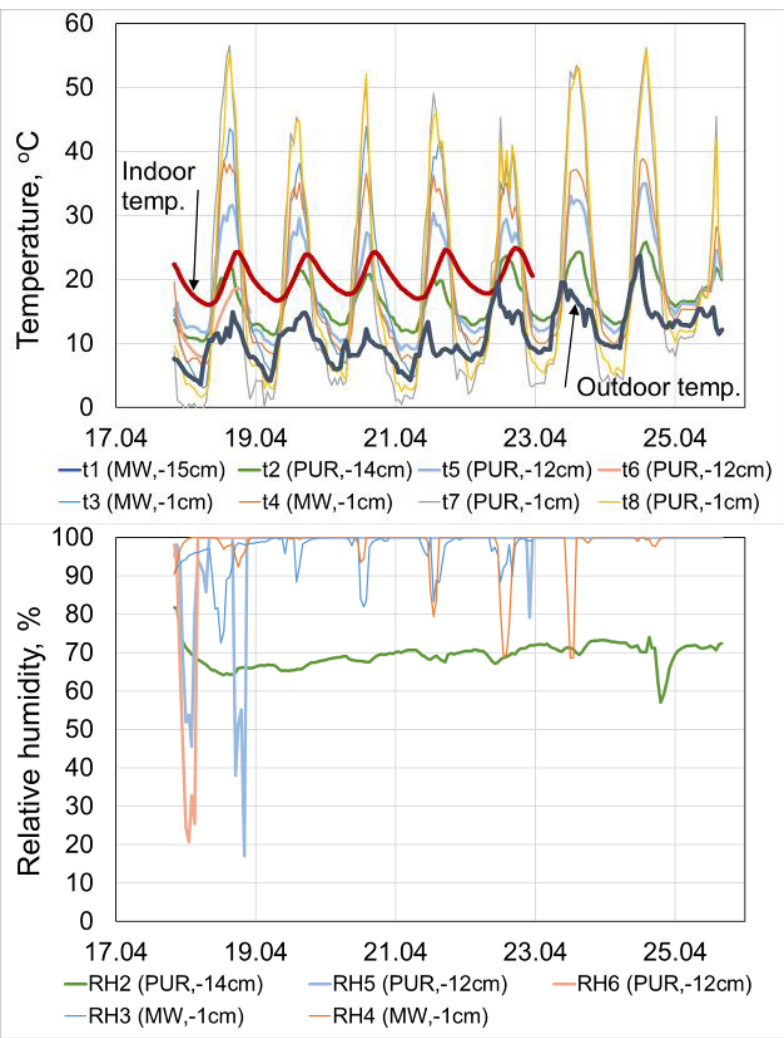

Fig. 4. Temperature (top) and relative humidity (bottom) below the waterproofing layer and below the insulation.

\section{Dimensional changes of SPF}

The analysis of the dimensional stability of SPF under specified temperature conditions showed that the average temperature change was $-0.001-0.002 \% /{ }^{\circ} \mathrm{C}$ So small a dimensional change cannot be the reason for blisters forming.

Nevertheless, after three temperature cycles up to $60{ }^{\circ} \mathrm{C}$, two specimens had localised internal damage on the bottom side of insulation at the end of the specimens, Fig. 5.

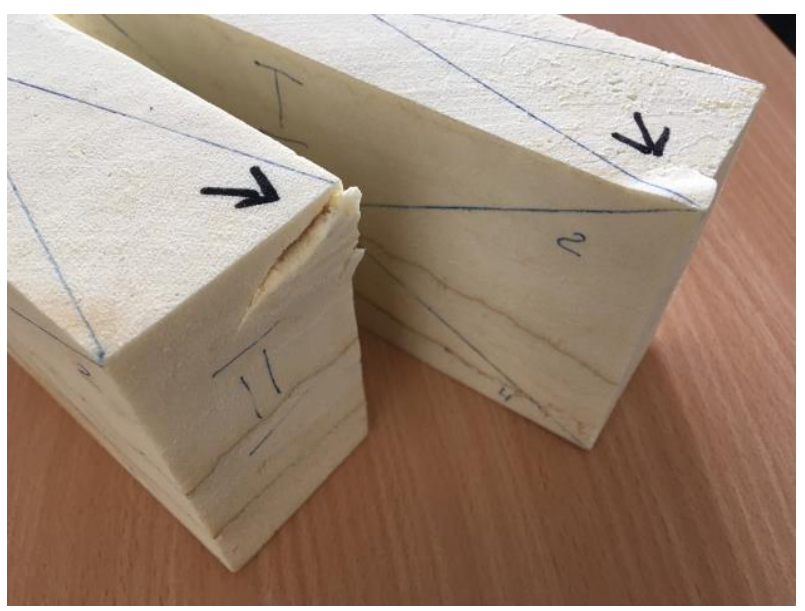

Fig. 5. Local damages after three temperature cycles.

\section{Moisture content of SPF}

To determine the moisture content of SPF, 22 samples were taken from the roof, and the moisture content for some of them was measured. The volumetric moisture content of samples from roof areas without water leakage was $0.1 \%$. The volumetric moisture content in areas with water leakage was $5.5 \%$ (varied between $4.8 \%-6.0 \%$ ). The moisture content by mass varied between $76 \%-95 \%$.

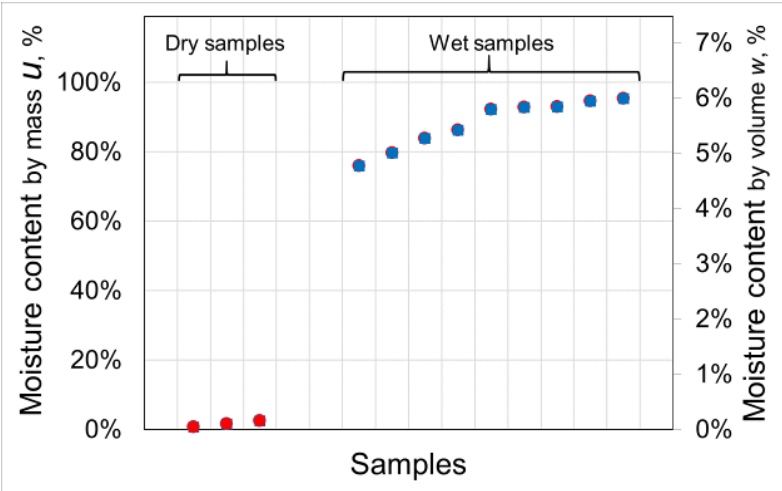

Fig. 6. Moisture content of the insulation depending on sampling location.

\section{Water vapour permeability}

The water vapour permeability of three sprayed polyurethane foam insulation layers (SPF) and two elastomeric coating layers (EC) was measured at dry cup $(11.3 \% / 43.2 \%)$ and wet cup $(95.3 \% / 43.2 \%)$ conditions.

High water vapour diffusion resistance (Fig. 7) indicates that quick water vapour distribution inside the foam is improbable. 


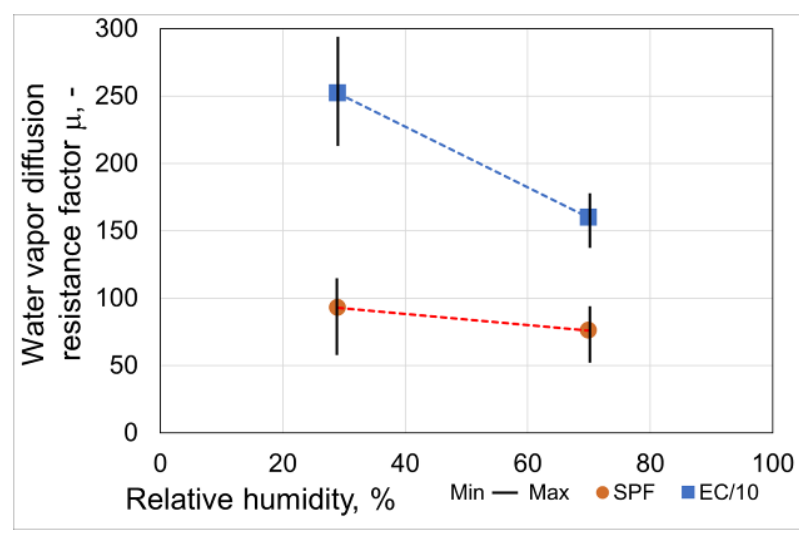

Fig. 7. Water vapour diffusion resistance factor for SPF and elastomeric coating (EC).

\section{The pull off strength of SPF}

From the 22 specimens that were drilled from insulation the pull off strength could be measured from 17 specimens because the remaining five specimens broke during specimen handling before any measurement could be done. Specimens were divided according to the UV degradation visually by darkness of the SPF on the layer of failure. Pull off strength was significantly $(\mathrm{p} \leq 0.05)$ smaller for more degraded (dark and very dark) specimens, Fig. 8.

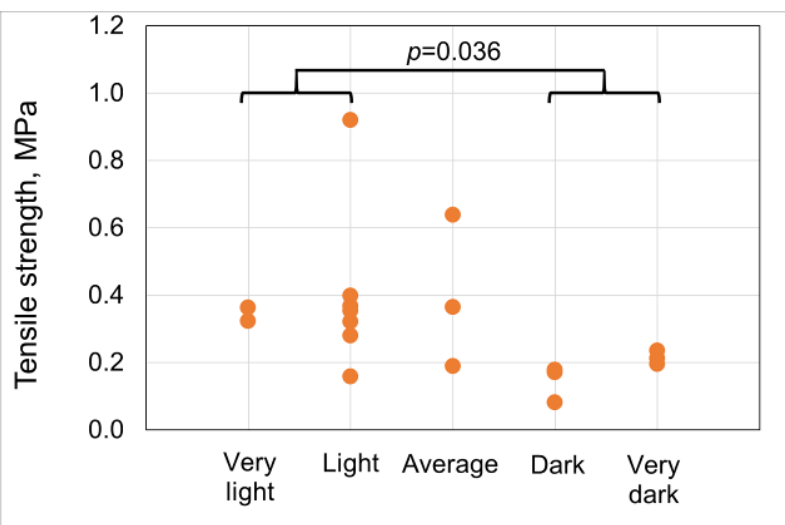

Fig. 8. Pull off strength of SPF at different levels of UV radiation degradation by colour.

For SPF specimens coloured as light and very light the failure on the pull-off test occurred always as an adhesive failure (between SPF layers). For SPF specimens coloured as dark and very dark mostly cohesive failure (failure of SPF itself) happened in the layer heavily degraded with UV radiation.

\section{Increase of water vapour pressure inside the SPF}

The equilibrium between water and water vapour depends on the temperature of the system. If the temperature of a two-phase system in equilibrium is changed, the pressure change of the system can be described according to the Clausius-Clapeyron equation. Clausius-Clapeyron equation pertains to the relationship between the pressure and temperature for conditions of equilibrium between two phases.

$\ln \left(\frac{P_{1}}{P_{2}}\right)=\left(\frac{\Delta H_{v a p}}{R}\right) \cdot\left(\frac{1}{T_{2}}-\frac{1}{T_{1}}\right)$

where:

$\Delta \mathrm{H}_{\mathrm{vap}}$ : The enthalpy of vaporization of the liquid (for water $40650 \mathrm{~J} / \mathrm{mol}$ ).

$R$ : The real gas constant, or $8.314 \mathrm{~J} /(\mathrm{K} \cdot \mathrm{mol})$.

$T_{1}$ : The temperature at which the vapour pressure is known (or the starting temperature).

$T_{2}$ : The temperature at which the vapour pressure is to be found (or the final temperature).

$P_{1}$ and $P_{2}$ : The vapour pressures at the temperatures $T_{1}$ and $T_{2}$, respectively.

Pressure change caused by changing temperature according to equation 1 is plotted on graph (Fig 10) for different starting temperatures. The maximum pull-off strength of heavily degraded layers of SPF is $0,4 \mathrm{MPa}$.

It is evident that water vapour pressure can exceed the tensile strength of interlayer bonding by a large margin if the temperature is changing as rapidly as measured (see Fig. 5). Calculations show that water vapour pressure of moist SPF is larger than the median measured pull-off strength of UV-degraded SPF layers.

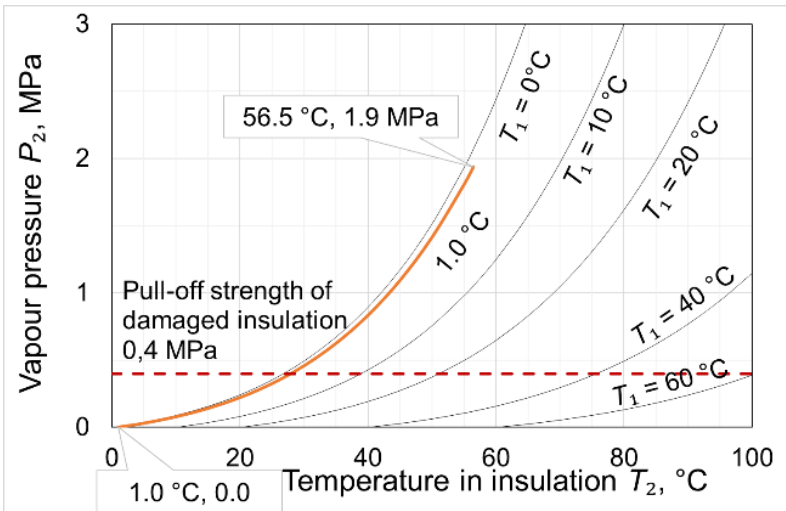

Fig. 9. Water vapour pressure dependence on temperature increase in moist SPF. 


\section{Realisation of risks in 2019 expected in 2011}

Quality control during construction (2011) listed several problems and their possible outcomes. All risks have realized during eight years:

Table 1. The main problems determined in 2011 and realized risks eight years later.

\begin{tabular}{|c|c|}
\hline Problem in 2011 [11] & Outcome in 2019 \\
\hline SPF surface was punctured. & Water flowed inside the SPF \\
\hline $\begin{array}{l}\text { SPF surface was not covered } \\
\text { with UV protection within } \\
24 \mathrm{~h} \text { after spraying. } \\
\text { Spraying the SPF on } \\
\text { surface degraded by UV } \\
\text { radiation. }\end{array}$ & $\begin{array}{l}\text { Weak connection between } \\
\text { SPF layers. } \\
\text { Separation of SPF layers. } \\
\text { Formation of blisters. }\end{array}$ \\
\hline $\begin{array}{l}\text { Spraying the SPF on the wet } \\
\text { concrete. Small blisters } \\
\text { were not eliminated. }\end{array}$ & $\begin{array}{l}\text { SPF adhesion with concrete is } \\
\text { low, water flows between } \\
\text { concrete and SPF. }\end{array}$ \\
\hline Water inside the SPF. & $\begin{array}{l}\text { Water evaporation and } \\
\text { formation of blisters. }\end{array}$ \\
\hline $\begin{array}{l}\text { Installation of UV protection } \\
\text { layer during unsuitable } \\
\text { climatic conditions }\end{array}$ & $\begin{array}{l}\text { The waterproofing and UV } \\
\text { protection layer is worn out. }\end{array}$ \\
\hline
\end{tabular}

\section{Conclusions}

The service life of the in-situ sprayed polyurethane foam insulation system roof was less than eight years. Most of the risks identified during a survey of the construction process were realised. SPFS constructed without temporary tent seems not to be durable and long-lasting roofing system in cold and humid climatic conditions

The roof was constructed without a temporary roof to protect the installed polyurethane insulation from solar radiation and precipitation. Also, temperature conditions during the construction period were unsuitable - mostly too cold.

Due to the very large roof area, it was difficult to follow the manufacturer's requirement to cover the foam to avoid the adverse effects of ultraviolet rays from direct sunlight, which can cause dusting and discoloration. Solar radiation quickly degraded the top surface of the in-situ sprayed polyurethane foam insulation, causing a weak connection between the foam layers. The water inside or below the foam evaporated during sunny days and broke the adhesion of different foam layers, which is considered the most realistic cause of separation of the SPF layers.

More and larger blisters are present on the southern side for two reasons. The initial degradation during spraying of the SPF was more intensive on the southern side. The change of temperature on sunny mornings is also more rapid on the southern side of the building, causing higher vapour pressure.

The analysis of hygrothermal performance, service life, and durability prediction should be included in the design process, especially for structures without practical durability and performance experience.
For materials whose performance depends strongly on installation, in addition to the certification of products and designers, the certification of installers and bluecollar workers is also unavoidable to guarantee the quality and designed service life of the building.

This research was supported by the Estonian Centre of Excellence in Zero Energy and Resource Efficient Smart Buildings and Districts, ZEBE (grant No. 20142020.4.01.15-0016) funded by the European Regional Development Fund, by the Estonian Research Council (grant No. PRG483) and European Commission through the H2020 project Finest Twins (grant No. 856602).

\section{References}

1. M. Salonvaara and J. Nieminen, in Proceedings of 6th Symposium on Building Physics in the Nordic Countries (Trondheim, Norway, 17-19 June, Pp. 239-246., 2002)

2. S. Geving and J. Holme, Journal of Building Physics 33, 249 (2010)

3. V. Paukštys, L. Šeduikyt, and A. Buska, in Proceedings of 9th Interantional Conference of Modern Building (Vilnius, Lithuania, 16-18 May, Pp. 131-135, 2007)

4. W. C. Cullen and W. J. Rossiter, in Int Symp on Roofs and Roofing (ISRR), Proc; Brighton, Sussex, Engl (1974)

5. R. L. Alumbaugh, E. F. Humm, and R. J. Keeton, Investigation of Spray-Applied Polyurethane Foam Roofing Systems-II (Port Hueneme, 1990)

6. T. Saadoja, Kodulinn Tallinn Nr 38 (Hometown Tallinn $\left.N^{\circ} 38\right)$ (2007)

7. M. Mändel and O. Orro, Construction History 27, 65 (n.d.)

8. H. Onton, Investigation of the Causes of Deterioration of Old Reinforced Concrete Constructions and Possibilities of Their Restoration, Tallinn University of Technology, 2008

9. M. Mändel and K. Õiger, Engineering History and Heritage 1 (2015)

10. G. Stainback, SprayFoam 2, 16 (2012)

11. H. Reinula, Quality Control of PU Foam (2011)

12. EN ISO 12572, Hygrothermal Performance of Building Materials and Products Determination of Water Vapour Transmission Properties - Cup Method (ISO 12572:2016) (Brussels, 2016)

13. EN 12086, Thermal Insulating Products for Building Applications - Determination of Water Vapour Transmission Properties (Brussels, 2013) 